J. Lake Sci.(湖泊科学), 2009, 21(5): 720-724

http://www.jlakes.org. E-mail: jlakes@niglas.ac.cn

(c)2009 by Journal of Lake Sciences

\title{
基于遥感和历史水位记录的鄱阳湖区淹没风险制图*
}

\author{
齐述华 ${ }^{1}$, 舒晓波 ${ }^{1}$, Daniel Brown ${ }^{2}$, 姜鲁光 ${ }^{3}$ \\ (1: 江西师范大学地理与环境学院, 南昌 330022) \\ (2: School of Natural Resources and Environment, University of Michigan, Ann Arbor, USA, 48109) \\ (3: 中国科学院地理科学与资源研究所, 北京 100101)
}

摘 要: 提出了一种利用多时相遥感影像和历史水位观测资料, 利用 ArcGIS 空间分析功能实现冲积平原区洪水风险制图的 方法. 首先利用 9 幅鄱阳湖区不同时相的 Landsat TM/ETM+遥感影像, 通过非监督分类的方法提取水体淹没范围. 根据都昌 水文站资料 1955-2001 年间水位记录, 分别计算鄱阳湖洪水多发期(6, 7, 8 月份)和全年各水位的超频率(EP). 假设在相同水位 条件下具有相同的淹没范围, 将遥感获取的水体边界作为 EP 的等值线, 在 ArcGIS 的支持下, 利用等值线插值实现鄱阳湖区 洪水多发期和全年的水体淹没风险制图.

关键词: 鄱阳湖; 淹没风险制图; 遥感; 超频率

\section{Flooding hazard mapping for Poyang Lake Region with remote sensing and water level records}

QI Shuhua ${ }^{1}$, SHU Xiaobo ${ }^{1}$, Daniel Brown ${ }^{2}$ \& JIANG Luguang ${ }^{3}$

(1: School of Geography and Environment, Jiangxi Normal University, Nanchang 330022, P.R.China)

(2: School of Natural Resources and Environment, University of Michigan, Ann Arbor, USA, 48109)

(3: Institute of Geographic Science and Natural Resources Research, Chinese Academic of Science, Beijing 100101, P.R.China)

Abstract: Flooding is a natural calamity that can caused great loss. Flooding hazard mapping is an effective tool for managing flooding to reduce the destructivity. In this paper, we suggested a new method to map the flooding hazard for alluvial plain with multi-temporal remote sensing images and lake level records. 9 images gained at different date for Poyang Lake Region were used to pickup the inundation extent with different lake level, and the annual and monthly exceedance probability of lake level for Poyang was estimated by sorting all lake level records. The boundary of inundation extent from remote sensing images was regarded as isolines valued as exceedance probability for the lake level happened on the image taken time. With the interpolation process provided by ArcGIS software, the flooding hazard were mapped for Poyang Lake Region.

Keywords: Lake Poyang; flooding hazard mapping; remote sensing; exceedance probability

湖泊生态系统是重要的湿地生态系统, 水是湖泊生态系统状态的最主要控制因子. 湖泊的水文过程 往往控制着湖泊周边冲积平原的洲滩植被空间分布特征，从而影响湖泊生态系统的野生动物空间分布特 征. 受季风气候影响，年际间季风的不稳定性造成了我国水旱灾害频繁发生. 长江流域中游地区, 洪水 发生频率显著增加，在汉朝-明朝(200BC-1644AD)洪水发生频率为 9-11 年一次，而 20 世纪最后的几十 年间, 洪水发生频率差不多是每 2-3 年发生一次 ${ }^{[1]}$. 洪水风险图可以广泛用于洪泛区管理、洪水保险、土 地利用规划、洪水避难、灾害预警、灾情评估、洪水影响评价、提高公众的洪水风险意识等重要作用.

* 国家自然科学基金项目(40801169)、江西省科技厅项目 “鄱阳湖湿地生态系统动态监测” 和国家科技支撑项目 (2007BAC23B05)联合资助.2008-11-11收稿；2009-02-19收修改稿. 齐述华，男，1973年生，博士，副教授；E-mail: qishuhua11@163.com. 
早在20世纪五、六十年代, 美国和日本等发达国家就开展了洪灾风险制图研究, 我国从20世纪80年代中 期开始开展洪灾风险研究 ${ }^{[2]}$. 随着空间技术在经济建设中应用的深人, 地理信息系统 (Geography Information System, GIS)和遥感技术成为洪水管理的重要工具, 比如许有鹏等 ${ }^{[3]}$ 在GIS技术支持下, 借助 历史洪水数据库和社会经济数据库, 探讨了流域洪水风险图快速编制的方法和途径; 苏布达等 ${ }^{[4]}$ 结合遥 感和GIS建立洪水淹没风险的模拟模型; 陈鹏霄 ${ }^{[5]}$ 应用GIS工具研究了ASAR遥感影像数据和DEM数据进 行东洞庭湖的水深制图和洪水频率制图的基础上制作东洞庭湖的洪水风险图; 唐川与朱静 ${ }^{[6]}$ 在GIS的支 持下对影响山洪形成与泛滥的地形坡度、暴雨天数、河网缓冲区、标准面积洪峰流量、泥石流分布密度 和洪灾历史统计六项因子进行了分析和叠合评价，并结合社会经济的易损性分析，完成了红河流域的山 洪灾害风险区划图.

本文拟利用不同时相的 9 幅Landsat TM/ETM+遥感影像，以非监督分类的方法提取的水体淹没范围， 并结合鄱阳湖中都昌水文站资料1955-2001年间水位记录计算不同水位发生的超频率，利用ArcGIS的空 间分析功能，实现鄱阳湖区洪水淹没风险制图.

\section{1 研究区概况}

鄱阳湖位于长江中游，承纳赣、抚、信、 修、饶“五河”来水, 通过调蓄后经湖口流人 长江. 受季风气候影响, 水旱灾害频繁发生, 造成鄱阳湖水位变化明显, 根据都昌水文站 水位记录, 1955-2001年间最高水位和最低 水位分别是 $20.60 \mathrm{~m}$ 和 $6.28 \mathrm{~m}$ (全文采用1985年 国家标准高程基准), 湖泊水位差异悬殊导 致湖泊形态差异悬殊, 呈现“高水为湖、低水 似河”和“洪水一片、枯水一线”的景观, 湖泊 水面面积变化在 $<1000 \mathrm{~km}^{2}$ 至 $>4000 \mathrm{~km}^{2}$ 之间 ${ }^{[7]}$. 从11-19世纪，鄱阳湖区共发生洪灾69次，平

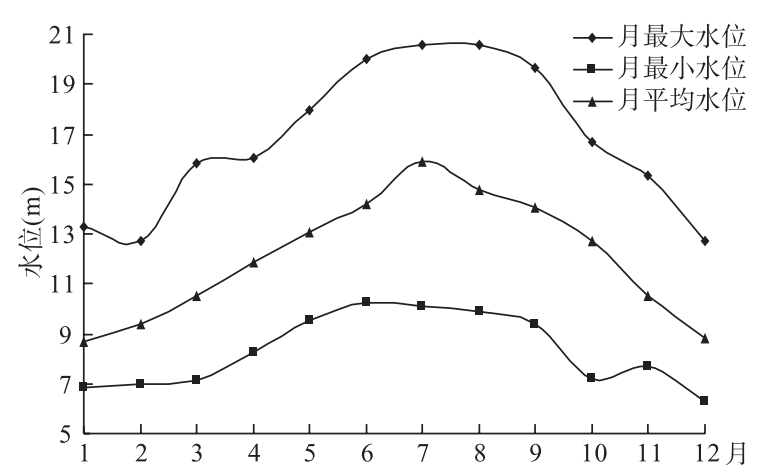

图 1 鄱阳湖都昌观测水位的月相变化特征

Fig.1 The lake level monthly dynamic for Lake Poyang 均13年一次, 进入 20 世纪初至90年代, 发生洪涝灾害37次, 平均2.7年一次, 表明洪涝灾害发生的频率已显 著增加 ${ }^{[8]}$, 并且洪水的强度也不断增加, 1998年洪水水位达到历史的最高记录. 在1955-2001年间, 分别于 1973, 1977, 1980, 1983, 1992, 1995, 1996, 1998和1999年发生了9次大洪水(洪水位>18.9m，都昌水文站水位), 其中历史最高水位发生在1998年的大洪水期间，都昌水位达到20.6m，超过发生在1995年的历史最高水位 $0.64 \mathrm{~m}^{[7]}$. 都昌水文站1955-2001年各月份的平均水位，鄱阳湖洪水主要发生在6, 7, 8和9月份(图1).

\section{2 数据与方法}

\section{1 遥感数据}

文中主要采用了美国Landsat卫星所获取的晴空条件下1987-12-17、1989-07-15、1993-01-31、 1993-07-10、1999-04-06、1999-12-10、2000-07-05、2000-08-22和2001-01-29等9幅TM/ETM+遥感影 像. 首先通过选择控制点将所有影像进行几何纠正，纠正的精度控制在1个像素点以内. 由于遥感影像的 数据来源不同, 影像的投影参数不一致, 因此文中结合DEM, 将所有影像的投影转换为横轴墨卡托投影 的正射影像. 对每幅遥感影像进行非监督分类提取水体范围, 由于鄱阳湖水面范围大，水体中悬浮物质 和污染物浓度、水体深度差异较大，导致水体的光谱特征有所差异，进行非监督分类时，同是水体会被划 分为不同的类别, 所以需要结合目视判读, 提取出水体范围. 并在ArcGIS软件支持下, 将栅格数据格式 下的水体淹没范围转换为淹没范围矢量, 得到水体淹没范围边界.

\section{2 圩堤数据}

鄱阳湖区围湖造田历史悠久 ${ }^{[9]}$, 目前圩堤纵横 $6400 \mathrm{~km}^{[10]}$ (图2), 根据圩堤的保护面积大小, 鄱阳湖区 圩堤划分为重点圩堤、重要圩堤和小圩堤, 1998年大洪水后, 鄱阳湖区实行退田还湖, 把部分小圩堤挖开, 
这部分圩堤又分为单退圩堤和双退圩堤. 除了圩堤倒塌的情况，通常圩堤内与鄱阳湖水体的联系是在人 为控制下, 不受湖泊水文地形条件的控制. 圩堤内部水体与湖泊水文站观测水位不存在水力上的联系, 圩堤内区域不作为水体淹没频率计算的范围.

\section{3 都昌水文站观测水位和淹水风险制图}

超频率(Exceedance Probability, EP) 是建立在多年历史观测资料统计基础上的, 为所有观测值中大于 某值的频率, 可以表达为:

$$
E P(x)=\frac{n}{N} \times 100 \%
$$

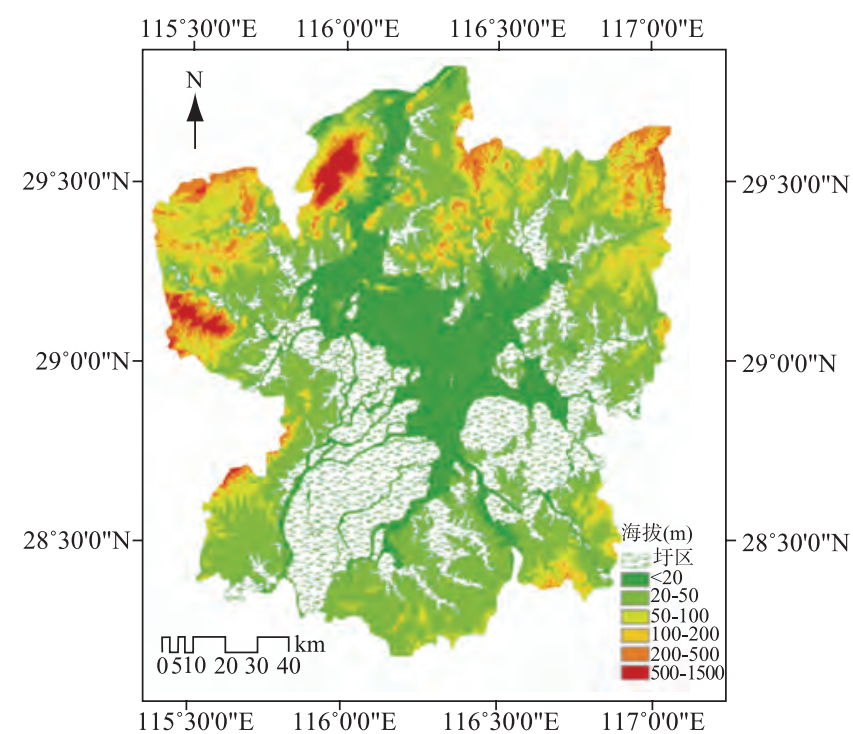

图 2 鄱阳湖区 DEM 和环湖圩堤分布

Fig.2 DEM for Poyang Lake Region and the levees distribution around Lake Poyang

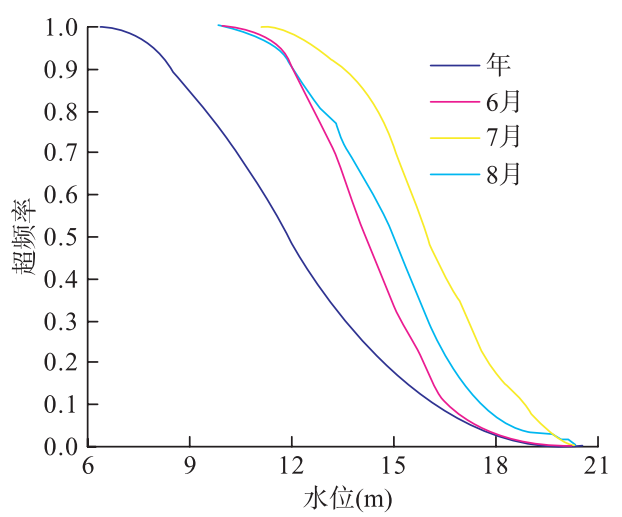

图 3 鄱阳湖年、 6 月、 7 月和 8 月份水位的超频率

Fig.3 The Exceedance Probability for every lake level based on lake level records from Douchang hydrological station during 1955-2001
其中, $x$ 为观测值, $n$ 为所有观测样本中大 于 $x$ 的样本数, $N$ 为总的观测样本数. 以 超频率为纵坐标、观测参数为横坐标形 成的超频率曲线表现为递减函数, 被广 泛应用于自然灾害事件(如气候异常事 件、水文灾害 ${ }^{[11-12]}$ 等)的发生频率预报中. 水位的超频率是根据多年历史水位记录, 大于某水位的频率. 由于鄱阳湖区洪水 主要发生在6-8月份, 所以在这里着重 分析6-8月份各水位发生的超频率，同 时也考虑了全年各水位的超频率.

假设水体的淹没范围只受水位的控 制, 那么水体淹没边界的淹没频率与该 淹没边界对应水位的超频率是相同的. 利用1955-2001年间每天的都昌水文站 水位, 利用(1)式计算遥感影像获取日期 的都昌水位的超频率, 并将遥感提取的 水体淹没范围边界线作为都昌水位的 $E P$ 等值线; 同时, 结合鄱阳湖区的DEM, 提取出鄱阳湖区高程小于历史最高水位 的范围作为鄱阳湖历史最大淹没范围, 并将提取的最大淹没范围转化为矢量, 作为 $E P=0$ 的等值线. 此外, 凡是高程大 于1998年最高洪水位的地区, 淹没风险 为 0 , 另外, 由于圩堤内的区域淹没风险 主要依赖于圩堤的结构和强度等, 在不 考虑圩堤内涝和溃堤的前提下, 认为淹 没风险为 0 . 最后, 通过最近邻内插方法, 实现鄱阳湖区圩堤外的年度、6月份、7 月份和8月份的水体淹没风险制图.

\section{3 结果与讨论}

\section{1 水位的超频率}

根据水位超频率的定义, 最高水 位的超频率等于 $1 / N$, 其中 $N$ 为总的水位 观测样本数, 而最低水位的超频率为 
100\%. 各遥感影像获取日期的都昌水位及该水位所对应的超频率见表1. 从超频率-水位曲线(图3)可以 看出, 超频率-水位曲线是递减曲线, 超频率随着水位的增加而减少; 相同水位下, 7月份水位超频率最大, 表明7月份高水位的发生频率最大，这与都昌水文站历年7月份的平均水位最大的结果(图1)是一致的.

表1 影像获取时间所对应的都昌水位及相应水位的超频率

Tab.1 The lake levels and the corresponding Exceedance Probability happened in these days that landsat images were taken

\begin{tabular}{llllll}
\hline Landsat 影像获取日期 & 都昌水位 $(\mathrm{m})$ & 年 $E P$ & 6 月份 $E P$ & 7 月份 $E P$ & 8 月份 $E P$ \\
\hline $1993-01-31$ & 8.32 & 0.919 & 1 & 1 & 1 \\
$1999-12-10$ & 9.29 & 0.816 & 1 & 1 & 1 \\
$1987-12-17$ & 9.73 & 0.774 & 1 & 1 & 1 \\
$2001-01-29$ & 11.03 & 0.623 & 0.988 & 1 & 0.972 \\
$1999-04-06$ & 11.48 & 0.562 & 0.966 & 0.998 & 0.962 \\
$2000-08-22$ & 13.72 & 0.294 & 0.585 & 0.890 & 0.702 \\
$2000-07-05$ & 15.54 & 0.137 & 0.260 & 0.605 & 0.398 \\
$1989-07-15$ & 17.35 & 0.045 & 0.054 & 0.274 & 0.121 \\
$1993-07-10$ & 18.36 & 0.021 & 0.020 & 0.144 & 0.054 \\
\hline
\end{tabular}

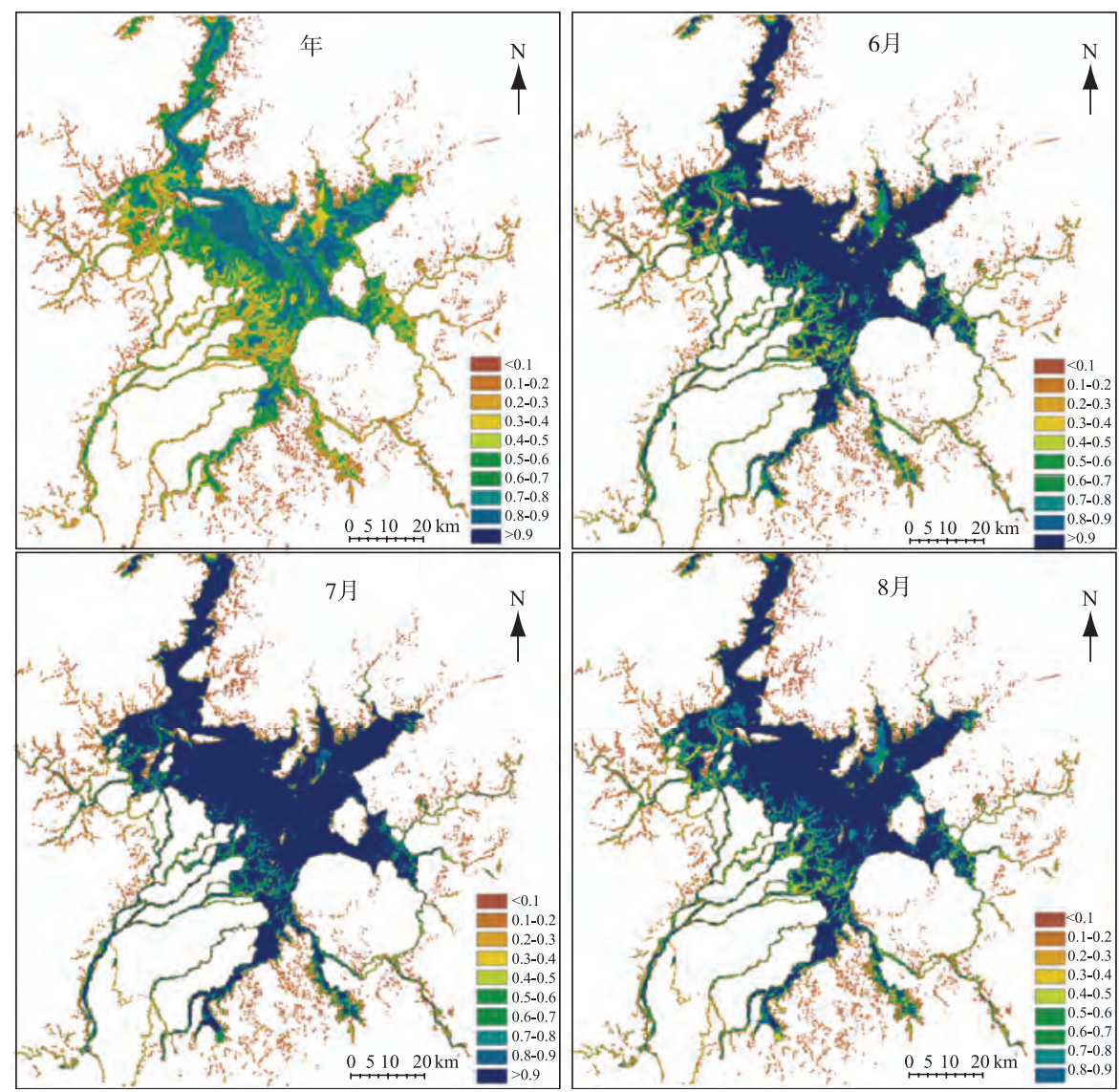

图 4 全年的和洪水多发月份的鄱阳湖区洪水淹没频率空间分布

Fig.4 The annual and monthly flooding probability for Poyang Lake Region 


\section{2 鄱阳湖区水体淹没风险制图}

利用ArcGIS空间分析模块的内插功能，采用最近邻内插方法，得到鄱阳湖区淹水发生频率空间分布 图(图4), 说明(1)年淹没频率空间分布图能够清楚地反映出常年淹水的范围, 与低水一线的景观吻合; (2)6月、7月和8月的淹没频率分布图能够反映鄱阳湖区基本处于高水位，特别是7月份，湖泊草洲基本都 处于淹没状态.

\section{4 结论与展望}

本文提出了一种利用历史水位观测数据和多时相的遥感数据, 在 GIS 的支持下实现湖泊洪水淹没风 险制图的新方法，并成功应用于我国洪水多发的长江中下游鄱阳湖区，实现了鄱阳湖区洪水季节 $6 、 7 、 8$ 月份和全年的洪水淹没风险制图.

由于鄱阳湖平原耕种历史悠久, 平原上广布着保护耕地和居民点的圩堤, 圩堤包围的区域的洪水淹 没风险很大程度上依赖于圩堤的结构、强度, 使该方法不能合理的评价圩堤内的洪水淹没风险, 而事实 上洪水造成的损失主要来自于圩堤内的农业损失和居民点的财产、人员损失等. 对圩堤内部的洪水淹没 风险的研究还有待进一步收集圩堤的建筑参数资料和历史事件的发生等资料, 实现这些区域范围的洪水 风险评估.

\section{5 参考文献}

[1] Yin H, Li C. Human impact of floods and flood disasters on the Yangtze River. Geomorphology, 2001, 41: 105-109.

[2] 黄大鹏, 刘 闯, 彭顺风. 洪灾风险评价与区划研究进展. 地理科学进展. 2007, 26(4): 11-22.

[3] 许有鹏, 李立国, 蔡国民等. GIS 支持下中小流域洪水风险图系统研究. 地理科学, 2004, 24(4): 452-457.

[4] 苏布达, 姜 䑣, 郭业友等. 基于 GIS 栅格数据的洪水风险动态模拟模型及其应用. 河海大学学报(自然科学版), 2005, 33(4): 370-374.

[5] 陈鹏霄. 基于 GIS 和遥感数据的洪水风险分析. 水利水电快报, 2008, 29(8).

[6] 唐 川, 朱 静. 基于 GIS 的山洪灾害风险区划. 地理学报, 2005, 60(1): 87-94.

[7] Shankman David, Liang Qiaoli. Landscape changes and increasing flood frequency in China's Lake Poyang Region. Professional Geographer, 2003, 55(4): 434-445.

[8] 《鄱阳湖研究》编辑委员会. 鄱阳湖研究. 上海: 上海科技出版社, 1988: 218-230.

[9] 吴金娣. 唐宋时期鄱阳湖区经济状况研究. 上海师范大学学报, 1997, (1): 43-50.

[10] 姜鲁光. 鄱阳湖退田还湖地区洪水风险与土地利用变化研究 [博士论文]. 北京: 中国科学院地理科学与资源研究所, 2006.

[11] Robert E Swain1, David Bowles, Dean Ostenaa. A framework for characterization of extreme floods for dam safety risk assessments. Proceedings of the 1998 USCOLD Annual Lecture, Buffalo, New York, 1998.

[12] Christopher M Smemoe. Floodplain risk analysis using flood probability and annual exceedance probability maps. Brigham Young Univerisity, 2004. 